\section{Southamp UNITY OF Southampton}

\section{Research employment, PhD training or sponsorship.}

Immunology Southampton is a multidisciplinary network of 40 principal investigators with over $£ 20$ m of funding devoted to the application of immunological discovery to the delivery of effective immunological solutions for the benefit of health and wellbeing. We bring together research across cancer, respiratory disease, neurodegeneration, infectious disease, rheumatology, dermatology and clinical immunology in three main themes: - Barrier immunity: understanding the importance of epithelial and endothelial barriers in tissue resilience and repair for example in the airways. - Interface immunology: understanding cell to cell and system to system functional interfaces such as antigen processing and presentation, iNKT function and systemic inflammation and brain function.

- Immunotherapeutics: including antibody mediated therapy in cancer and inflammatory disease and vaccine development for cancer and infectious disease.

Our translational research is underpinned by:

- Validated, GLP level immunometry in a dedicated laboratory

- Close collaborative links with the physical sciences, electronics, engineering and computer science - especially in the development of new human explant models and immunometry-on-a-chip devices

Close links with the pharmaceutical and biotechnology industries

- Excellent training in clinical and non-clinical translational immunology including an affiliated integrated $4 y \mathrm{r} \mathrm{PhD}$ programme.

For enquiries regarding research employment, $\mathrm{PhD}$ training, or sponsorship of externally funded fellowships, please contact Tim Elliott: t.j.elliott@southampton.ac.uk +44(0)2380796193

www.southampton.ac.uk/medicine

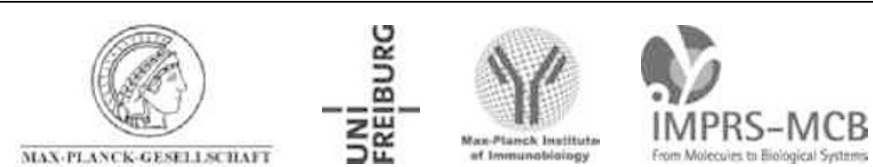 \\ International Max Planck PhD Program IMPRS for Molecular and Cellular Biology \\ is looking for \\ students with strong motivation and talent for first class basic research in}

\section{Immunology, Epigenetics, Developmental Biology,} Bioinformatics and Proteomics

You will:

- Work on exciting scientific projects addressing the hot topics of molecular and cellular biology in various systems

- Receive full funding for the whole time of the PhD (3-4 years)

- Rotate in 3 laboratories before you start your $\mathrm{PhD}$ project

- Enjoy the benefits of a state-of-the-art scientific institute with first-class facilities

- Be part of a vibrant international research community - official language is English

- Benefit from intensive practical and theoretical education and complementary skills courses

IMPRS-MCB PhD program is organized by the Max-Planck Institute of Immunobiology and Epigenetics and the University of Freiburg. Our scientists are publishing in the high impact factor journals and are internationally renowned experts in their fields. You will have a chance to regularly meet international speakers at the institute and at conferences.

You have MSc, MRes, Diploma or an equivalent degree in Biology, Biomedicine, Chemistry or related sciences. The degree should be awarded latest 6 months after the application deadline. You have several months of practical lab experience working on a scientific project, excellent English language skills and wish to work in a dynamic international team.

More information about the program and how to apply you will find on our web page: www.imprs-mcb.mpg.de

Application deadline for autumn term: $31^{\text {st }}$ May 2011

\section{College of Life Sciences}

\section{DUNDEE}

The Division of Cell Signalling and Immunology within the College of Life Sciences is currently seeking new group leaders to extend and strengthen our current range of activities. The interests of the current members of the Division are diverse and focus on the control of the innate and adaptive immune system as well as on the signalling cascades that control cellular energy balance, cell growth, nutrient sensing and mRNA stability and translation. Please see our Divisional and lab webpages for more information: http://www.lifesci.dundee.ac.uk/research/csi.

We wish to recruit new group leaders who propose to tackle key problems in immunobiology and cell signalling using the full range of research tools available including in vivo approaches that utilise disease models, intravital microscopy and other imaging methods and proteomic and other systems biology scale studies.

We would like to hear from individuals at any career stage including those who are looking for an opportunity to set up their own lab for the first time. The College of Life Sciences offers a supportive environment with exceptional infrastructure and facilities and offers particularly good opportunities for collaborations across different disciplines. It is one of the most active and productive research institutes in Europe and currently hosts researchers from 54 different countries. The local area is one of outstanding natural beauty and combines a high quality of life with a low cost of living. For more information please visit: http://www.lifesci.dun dee.ac.uk/.Applications should include a CV and a statement of research interests and plans. Informal enquires are welcome and can be made to the current Head of the Division, Prof. Colin Watts (c.watts@dundee.ac.uk, +44-1382-384233) or to the Head of the College Prof. Doreen Cantrell d.a.cantrell@dundee.ac.uk.

To apply on-line please visit:

www.dundee.ac.uk/jobs. If you are unable to apply on-line please contact Human Resources on (01382) 386209 (answering machine) for an application pack. Please quote reference number LS0069.

Applications are invited up to 1st July 2011.

The University of Dundee is committed to equal opportunities and welcomes applications from all sections of the community. The University of Dundee is a Scottish Registered Charity, No. SC015096.

U212353R

"When trying to recruit good scientists for

such a remote institutions like ours, in the

Canary Is., the high visibility and wide-range

exposure that Naturejobs provides has been

crucial. I'm very happy to have international

candidates who applied to our position from

places ranging between St. Petersburg and

Cincinnati. Thanks a lot!”

Eduardo Salido, MD, PhD,

Hospital Universitario de Canarias 
We are now accepting applications for our Postdoctoral Program where you will have an opportunity to develop your professional potential and gain valuable experience from some of the top minds in the biopharmaceutical industry. We are seeking PhD talent for a 3-year assignment. Positions are available in Gaithersburg, Maryland; Santa Clara and Mountain View, California; and Cambridge, UK.

Explore our Fellowship opportunities in areas of biotechnology discovery and product development including:

- Infectious Disease

- Oncology

- Respiratory \& Inflammation

- Biopharmaceutical Development

- Translational Science

- Protein Engineering

World-class mentoring • Competitive salary and benefits, 401(k), and bonus potential!

Learn much more at: www.medimmune.com/careers

Click on the "Our Opportunities" tab and search "Postdoctoral".

Advancing Science and Medicine to Help People Live Better Lives

Copyright ( 2011 Medlmmune, LLC. All rights reserved.

Medlmmune is an Equal Opportunity Employer.

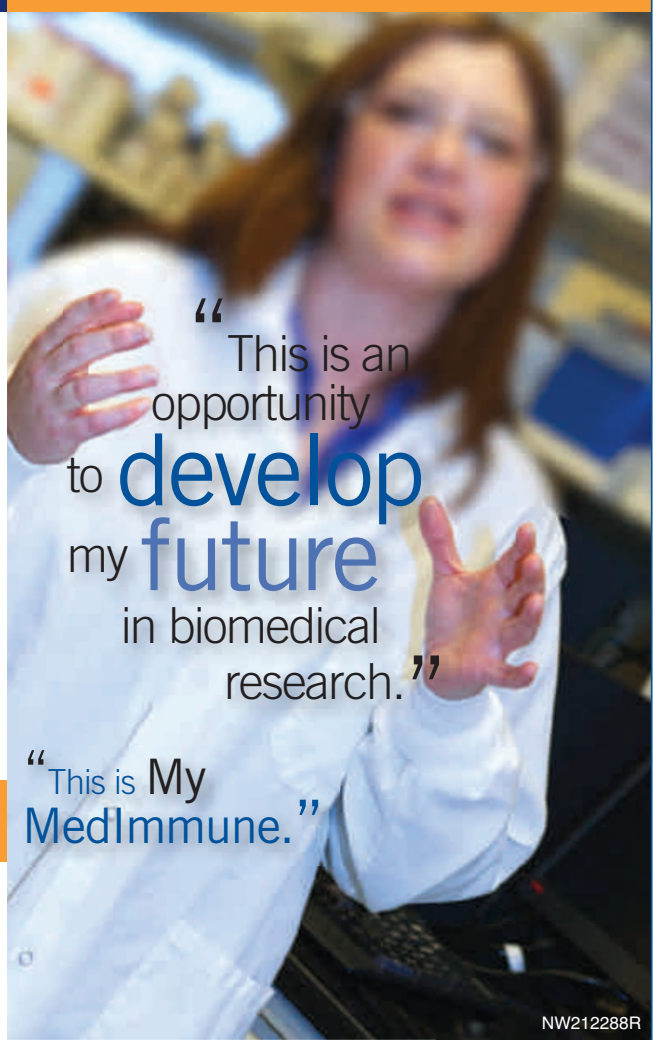

\section{University of Washington, Seattle \\ Department of Pediatrics Seattle Children's Research Institute}

The recently established Center for Childhood Cancer of the Seattle Children's Research Institute (SCRI) invites applications for two fulltime faculty positions (Assistant Professor, Associate Professor or Professor, without tenure) from established investigators whose research is focused on tumor immunology and/or translational aspects of cancer immunotherapy. The Center's research vision is to discover and refine to practice effective forms of cancer immunotherapy for children through integrative team research. The applicant's area of research interest should be complementary to the interests of current faculty working on $T$ cell genetic engineering for cancer adoptive therapy and ideally take advantage of the Center's Process Development and cGMP cell production unit, as well as, the extensive collaborative opportunities with the Fred Hutchinson Cancer Research Center and the University of Washington. Responsibilities of the position include development of an independent, extramurally funded research program and teaching and mentoring graduate students, post-doctoral fellows and junior faculty investigators. The successful candidate must have a $\mathrm{PhD}, \mathrm{MD}$, or $\mathrm{MD} / \mathrm{PhD}$. Address any inquiries to Dr. Michael Jensen, Center Director, at michael.jensen@seattlechildrens.org.

University of Washington faculty engage in teaching research and service. The University of Washington is an Equal Opportunity/Affirmative Action Employer. Women and minorities are encouraged to apply.

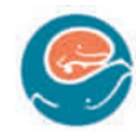

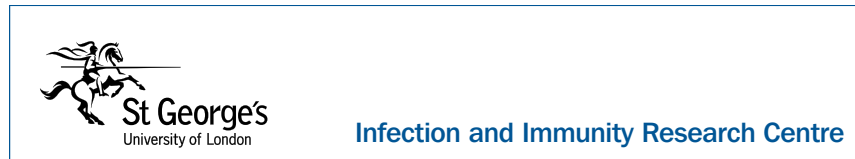

\section{New positions available at Chair and Senior Lecturer level}

The Infection and Immunity Research Centre at St George's represents a grouping of 24 Principal Investigators focused on tackling infection problems at the diagnostic, therapeutic and preventive level. Key areas include immune responses to infection, vaccinology, molecular parasitology, fungal and mycobacterial therapeutics, innate immunity, and microbial genomics. We have an international and tropical perspective with extensive well-established overseas collaborations. We have state of the art laboratory facilities including a newly commissioned suite of Category 3 laboratories. Our strong clinical translational emphasis is supported by a Clinical Research Facility and a dedicated Vaccine Institute, and is facilitated by co-location with the St George's Hospital NHS Trust on our South-West London campus.

\section{Opportunities}

The Research Centre is expanding and this has created new opportunities at senior level for established scientists or clinical scientists with a strong and developing research portfolio. Appointments come with an attractive package, including funding for support staff.

\section{Contact details}

www.sgul.ac.uk/research/centres/ii

To discuss these positions further, please contact either of our Joint Heads of Research Centre:

Professor Julian Ma (0208 725 5818, jma@sgul.ac.uk) or

Professor Derek Macallan (0208 725 0283, macallan@sgul.ac.uk) 